University for Business and Technology in Kosovo

UBT Knowledge Center

UBT International Conference

2015 UBT International Conference

Nov 7th, 9:00 AM - 5:00 PM

\title{
Estimating quarter to quarter economic growth in Kosovo
}

\author{
Ledjon Shahini \\ University of Tirana, ledjonshahini@feut.edu.al \\ Bernard Dosti \\ University of Tirana, bernarddosti@feut.edu.al \\ Perseta Grabova \\ University of Tirana, persetagrabova@feut.edu.al
}

Follow this and additional works at: https://knowledgecenter.ubt-uni.net/conference

Part of the Business Commons

\section{Recommended Citation}

Shahini, Ledjon; Dosti, Bernard; and Grabova, Perseta, "Estimating quarter to quarter economic growth in Kosovo" (2015). UBT International Conference. 34.

https://knowledgecenter.ubt-uni.net/conference/2015/all-events/34

This Event is brought to you for free and open access by the Publication and Journals at UBT Knowledge Center. It has been accepted for inclusion in UBT International Conference by an authorized administrator of UBT Knowledge Center. For more information, please contact knowledge.center@ubt-uni.net. 


\title{
Estimating quarter to quarter economic growth in Kosovo
}

\author{
Ledjon Shahini ${ }^{1}$, Bernard Dosti ${ }^{2}$, Perseta Grabova ${ }^{3}$ \\ 1,2,3 Faculty of Economics, University of Tirana, Albania \\ ledjonshahini@feut.edu.al ${ }^{1}$, bernarddosti@feut.edu.al ${ }^{2}$ \\ persetagrabova@feut.edu.al ${ }^{3}$
}

\begin{abstract}
Estimation of economic growth in real time is one of the main objectives for most of the policymakers. At this point Gross Domestic Production at quarterly frequencies is the most accurate indicator. Most of the countries that have developed this macroeconomic indicator are publishing GDP in two main forms, seasonal and not seasonal adjusted. Seasonality is a present phenomenon for most of the economic sectors at quarterly frequencies. These different rhythms caused by weather, human habits, legislation, and so on, tend to repeat themselves periodically. It is therefore natural to try to estimate their impact and take account of them in the analysis of quarterly time series. Seasonal adjustment serves to facilitate the comparisons between periods especially in the linked periods. These adjustments tried to avoid phenomena like the increase of employment in agriculture or accommodation sector during summer because of production cycle and the increase number of tourists. In this paper it will be presented a method how to do seasonal adjustment on quarterly GDP by production approach in case of Kosovo. The paper details an application of Tramo and Seats method using, to seasonal adjustment and trend-cycle estimation. Based on sector analyses will be discussed the important problem of the choice between direct and indirect adjustment of quarterly series.
\end{abstract}

Keywords: Economic growth, Seasonal adjustment, Quarterly GDP

\section{Introduction}

Time series consist of several components, such as trend, cycle, seasonality and irregular component. The breakdown of these elements in the time series is a known phenomenon and has attracted the attention of statisticians and economists. To understand what real is happening in the last period it is very important to analyze the series without these effects. For quarterly time series, like as quarterly GDP, one of the most important components is the season effects. The importance of having quarterly GDP seasonal adjusted is very large as it shows the fluctuations of real economy in the short run. Most of the policymakers are very interest about the efficiency of their decision in short run. At this point the economic growth can't be estimated as a comparison of actual period with the same one of the previous year. What is needed is a quarter to quarter comparison which can be estimate only in a series without the presence of seasonality. As we will explain later on to do seasonal adjustment on quarterly GDP for estimating growth rate, it is very important that the series in constant prices to be expressed at reference year of one period, otherwise the seasonality is influenced even from the impact of price changes.

The analysis of the estimation and removal of the seasonal component means using analytical techniques to decompose a series into its components. The purpose of this process is to provide a better understanding of the behavior of the time series. The relationship between the original series and its trend-cycle, seasonal, and irregular components can be modeled as additive or multiplicative form, so it can be expressed as:

- $\quad$ Additive Model: $X_{t}=S_{c t}+T_{t}+I_{c t}$

- $\quad$ Multiplicative Model: $X_{t}=S_{c t} * T_{t} * I_{c t}$

The multiplicative model assumes that the absolute size of the components of the series are dependent on each other and thus that the seasonal fluctuation size increases and decreases with the level of the series, a characteristic of most seasonal macroeconomic series. Additive models on the other hand are 
more suitable for the series in terms of volume. To determine which of the models is better, we should start from the amplitude of the seasonal component.

Seasonal adjustment is normally done using programs, most commonly worldwide by one of the programs in the X-11 family. In the early 1980s, one of the alternative methodology for seasonal adjustment of time series, was "ARIMA-model-based" (AMB) approach, were used (Hillmer and Tiao 1982). Other programs in common use include the Tramo-Seats package developed by Bank of Spain and promoted by Eurostat.

In this paper we will apply Tramo-Seats technique to quarterly GDP by production approach series for Kosovo. It is important to mention that quarterly GDP in constant prices for Kosovo is estimated with prices of previous year. In this condition firstly the series are chain-linked and after that is done seasonal adjustment. The objective of the paper is to show the quarter to quarter growth rate for Kosovo as an important indicator for short term movement of the economy.

\section{Seasonality and its components}

It is a known phenomenon that many economic series have a significant component that is constantly repeated with a specific frequency over time. These effects repeated on a regular basis are known as seasonal effects. Ignoring these effects can lead to misinterpretation of our data, but at the same time we must be very careful to the determination of these components. Often it is necessary not to use the best method of seasonal adjustments, but to provide better economic representation of the series. The causes of seasonal fluctuations in economic data are often of different natures and sometimes loss the primary meaning of seasonal effects. Because of their regular recurrence those have to be treated as such effects and can be grouped at least into four main categories:

Calendar: Certain public holidays, like Independence Day, Eid and Christmas, have a clear effect in some series, particularly those related to production. Many series are built on the calendar working days each month. Holidays in turn, brings changes in the number of working days which shift the process of production or the imports of goods. These changes can lead to false connection between otherwise unrelated series. So far calendar effects are included in these components:

- $\quad$ calendar effects;

- $\quad$ working-days;

- $\quad$ trading-days;

Even it is very difficult to distinguish calendar component from seasonal component, the estimation is necessary for comparisons purposes on a year-to-year basis. The calendar component is very often slightly moving and may disturb the stability of the seasonal figure. Calendar effect: The first meaning of calendar effects is closely linked with economic activity around some special dates a year, like Christmas or Easter (Fischer 1995, Planas 1997). These special dates are usually associated with increased sales volume. Christmas effect on economic activity is always in the fourth quarter, while the other holidays can move in different quarters. These movements mean seasonal volatility pattern from one year to another. For this reason, holidays require a specific statistically treatment, and often are treated as dummy variables in the model. Working-days: Often various businesses or activities are related with working days ${ }^{22}$ during weeks. Number of working days varies from one month to another and this can appear as seasonal effect when we do annual comparisons. A quarter can have a day job more than the same quarter of previous year, for example. This effect is corrected in the series mainly relating to regular working-days. Trading-days: Whilst the working-day effects emphasize the distinction between business activities during the week and weekend, the trading-day effect catches the differences in the economic activity among the days of the week. A regression approach, based on dummy variables is normally used to correct the trading-day effect. If it is correctly applied, the regression approach to detect the trading-day effect includes the detection of the working-day and of the calendar effect.

Timing decisions: The timing of the period of settlement of tax liabilities of companies, starting and ending days of school, period of employee bonuses, are all example of decisions made by individuals or institutions that cause significant seasonal effects. These decisions are not necessarily associated with any particular period of the year, but experience has shown that tend to occur in the same period

22 (i.e. Monday, Tuesdays,..., Friday) and the weekend days (Saturday and Sunday) 
each year. These are decisions that produce evident seasonal components in series such as employment rates.

Weather: Weather variables such as rainfall, temperature changes have direct effects on various economic series, such as agriculture, construction and transport. The effects of these factors can be considered as true seasonal effects as resulting from the annual movement of the earth's axis which leads to the formation of the seasons. Natural not foreseen phenomena can lead to large random effects.

Expectation: Expectations often become a source of seasonal effects. The expectation of toys sales growth at the end of the year leads to increased production of toys in a previous period. Also expectations are often associated with the business cycle, creating seasonal effects in many economic series. Their assessment is based on historical data as there is no fixed rule of their recurrence. Seasonal effects in some sectors may be present without expectations, but in this case are more natural effects.

These four groups can be assumed as the main causes of seasonal effects. Often these factors are not distinct from each other and sometimes have indirect impact on the series. If bad weather results in damage to agricultural products, this will increase the price of these products, for example. So we can say that the causes of seasonal components can be different and that they can't be assumed as deterministic. However it would be unreasonable to assume that all seasonal components are known for a series. Although some factors can be considered as deterministic as calendar effects and decision making, others, such as weather and expectations, are not deterministic and can't lead to deterministic seasonal pattern. Often these factors are negatively affecting an optimal arrangement of a series of seasonal effects

Before we turn to the problem of how seasonality is determined, it is necessary to mention the economic series that have clear seasonal effects and those that do not have. Types of series that have regular seasonal pattern are generally those that deal with production, sales, revenues and government spending, imports and exports. Series that do not have regular seasonal component includes prices, interest rates, and exchange rates. If we will generalize this rule, variables that require regular adjustment are those that require planning or those who require long-term decision making, while not regular are usually those variables that can change rapidly in value, or seeking a short-term decision making.

\subsection{Direct versus Indirect approach}

Many time series are constructed as aggregate of several component series. Estimates of the seasonal effects in such aggregate series may depend on the level of aggregation at which seasonal adjustment methods are applied. It is important to analyze the level of aggregation at which component series are seasonally adjusted. If the series used are too disaggregated, the degree of noise/irregular movement can be much larger and possibly overshadow the seasonal factors in the series. An acceptable seasonal adjustment of a series implies that the series is stable and doesn't display any residual seasonality. Stability of a series implies that the series is not heavily revised when the seasonal adjustment model is reapplied. If seasonal adjustment is applied directly to an aggregate series, the resulting aggregate does not necessarily equal the sum of its seasonally adjusted components.

Direct approach: in the direct method firstly indicators are aggregated data and then seasonally adjusted. Direct adjustment tends to perform better when all component series display similar seasonal patterns and when aggregation leads to some noise cancellation between the component series.

Indirect approach: Indirect seasonal adjustment is simply a way of seasonally adjusting a series by directly seasonally adjusting its parts. Indirect adjustment occurs when the component series of an aggregate are each individually examined for seasonal effects and the seasonally adjusted aggregate series is then calculated by summing these seasonally adjusted component series.

In general, if the components that compose an aggregate series have quite distinct seasonal effects and the data are of good quality, indirect method is preferable to direct methods. However when the components that compose an aggregate series even though they have different seasonal effects, but precise determination of seasonal components is difficult, then a summary of the series may result in cancellation of these problems. In this case the direct seasonal adjustment method usually results in a better quality than indirect method. In other situations, it is not clear which method is the best, but a good understanding of factors affecting the series, is necessary to specify the method to be used. 
The most widely used seasonal adjustment techniques are X-12-ARIMA and TRAMO-SEATS which can handle the direct and indirect methods nicely. Both of the techniques are part of Demetra software developed by EUROSTAT.

\section{Consistency between annual and quarterly accounts}

It is important that quarterly estimates to be consistent with annual one. They should be based on the same sources as the annual accounts, and should follow the same methodology. However, in practice, this may not always be possible and for this reasons different methods are used. Methods used for balancing diverse, from manual adjustment, to more complicated models such as mathematical procedures for dealing with large matrices. Basically, we can mention same methods as the main one.

Manual methods - the simplest way to balance the data is to regulate the quarterly data manually, combining knowledge of a series with the ability to manual application. This method is used in the case when the difference between quarterly and annually data are small and where few series should be adjusted.

Proportionate method - It is based on the distribution in the form of a report. For this reason are created the ratios of each quarter to the amount of four quarters which are applied to the annual value. Mathematically this method can be expressed as:

$$
\begin{array}{r}
X_{t, v}=A_{v}\left(\sum_{t, v}^{4} I_{t, v}\right) \\
X_{t, v}=I_{t, v}\left(\sum_{v}^{4} I_{t, v}\right)
\end{array}
$$

(eq. 1)

(eq. 2)

Where:

$$
\begin{aligned}
& \mathrm{X}_{\mathrm{t}, \mathrm{v}} \rightarrow \text { Value of Quarter " } \mathrm{t} " \\
& \mathrm{~A}_{\mathrm{v}} \rightarrow \text { Annual Value "v" } \\
& \mathrm{I}_{\mathrm{t}, \mathrm{v}} \rightarrow \text { Quarter Indicator " } \mathrm{t} "
\end{aligned}
$$

Denton Method - This method consists in finding the minimum square of differences of two consecutive values, provided that the sum of the four quarters to be equal to the annual. So mathematically we would find:

$$
\begin{array}{r}
\underset{\left\{X_{1}, \ldots . X_{4 v}, \ldots \ldots X_{T}\right\}}{\min } \sum_{t=2}^{T}\left[\frac{X_{t}}{I_{t}}-\frac{X_{t-1}}{I_{t-1}}\right]^{2} \quad \text { (eq. 3) } \\
\mathrm{t} \in\{1, \ldots . .(4 \mathrm{v}) \ldots . . \mathrm{T}\} \text { dhe nën supozimin se: } \sum_{\mathrm{t}=2}^{\mathrm{T}} \mathrm{X}_{\mathrm{t}}=\mathrm{A}_{\mathrm{k}} \text { për } \mathrm{k} \in\{1, \ldots . . \mathrm{v}\}
\end{array}
$$

Where:

$$
\begin{aligned}
& t \rightarrow \text { quarter } \\
& x_{t} \rightarrow \text { Quarterly value } \\
& I_{t} \rightarrow \text { indicator used to quarter } t \\
& A_{k} \rightarrow \text { annual value for the year } k \\
& v \rightarrow \text { annual value for the last existing data } \\
& T \rightarrow \text { value for the last quarter of existing data }
\end{aligned}
$$


Application of this method has the advantage that keeps the trend of indicators much better than a proportionate approach when moving from one year to another without changing the annual amount. In addition to the methods mentioned above, there are many others, which are based on regression analysis of the series, such as ARIMA methods proposed by Hillmer and Trabelsi (1987), or even GLS (Generalized Least Square) models proposed by experts of the Institute of Canadian statistics. These models find use in cases where the series are stable or when the user has more detailed information on indicators.

\section{Chain-Link Process}

In many cases, different periods are not comparable with each other. More concretely is the case when comparing GDP at constant prices expressed with prices of previous year. In this case that two data are not possible to be compared because they tell nothing about the economy growth. Chain link process is used exactly for comparing data at different periods. This procedure does not have a reference period or base period, it produced a series which enable indexes become comparable with each other despite the frequency that they have. There are three well-known methods such as:

- Annual overlap

- Quarter overlap

- Over the year

Annual overlap method consists in creating a link factor between the inter-annual values. In this method the average prices of last year are used as weights for each quarter of the current year who is multiplied by a factor connector derived from the annual data. Arithmetically it will be expressed as:

$$
F_{v}=\frac{\sum_{i=1}^{n} \sum_{j=1}^{4} p_{i}^{j, v-1} q_{i}^{j, v-1}}{\sum_{i=1}^{n} \sum_{j=1}^{4} \bar{P}_{i}^{v-2} q_{i}^{j, v-1}}
$$

Where:

$$
\begin{aligned}
& \mathrm{F}_{\mathrm{v}}-\text { linked factor } \\
& p_{i}^{j, v-1} \text { - Process of quarter } \mathrm{j} \text { for year } \mathrm{v}-1 \\
& q_{i}^{j, v-1} \text { - Quantity of quarter } \mathrm{j} \text { for year } \mathrm{v}-1 \\
& \bar{P}_{i}^{v-2} \text { - Average process of year } \mathrm{v}-2
\end{aligned}
$$

Multiplying the value of quarter i of year $v-1$ with average process of year $v-2$, it is possible that it can be compared with quarters of year $\mathrm{v}$ expressed with average prices of year $v-1$. If it is a fully consistence between quarterly and annually values than linked factor explained in equation above will be identical with the other one that is used for linking annual data of year $v$-lexpresed in process of $v-2$ with year $\mathrm{v}$ expressed with process of year $v-1$.

$$
F_{v}=\frac{\sum_{i=1}^{n} \sum_{j=1}^{4} p_{i}^{j, v-1} q_{i}^{j, v-1}}{\sum_{i=1}^{n} \sum_{j=1}^{4} \bar{P}_{i}^{v-2} q_{i}^{j, v-1}}=\frac{\sum_{i=1}^{n} P_{i}^{v-1} Q_{i}^{v-1}}{\sum_{i=1}^{n} \bar{P}_{i}^{v-2} Q_{i}^{v-1}}
$$

Where:

$$
\begin{aligned}
& P_{i}^{v-1}-\text { Process of year v-1 } \\
& Q_{i}^{j, v-1} \text { - Quantity of year v-1 }
\end{aligned}
$$


Quarter overlap method consists on creating a linked factor for one quarter. This method is based on average process of actual and previous year. To link four quarters of year $v-1$ expressed with process of year $v-2$ with four quarters of year v expressed with process of year $v-1$ is created a ratio index as a quarter of year $v$ with four quarters of year $v-1$. Mathematically it means:

$$
F_{t}=\frac{\sum_{i=1}^{n} \bar{P}_{i}^{v-1} q_{i}^{4, v-1}}{\sum_{i=1}^{n} \bar{P}_{i}^{v-2} q_{i}^{4, v-1}}
$$

Multiplying the value of quarters with this index can obtain data comparable with each other. This method has an advantage compared with the previous one when are compared the first quarter of the year $v$ with the fourth quarter of year $v-1$.

Over the year method in deferent way from the other methods needs two linked factors. Each quarter of year $\mathrm{v}-1$ expressed with prices of year $\mathrm{v}-2$, needs to be multiplied with respective link factor. In this case all quarters are estimated with average prices of previous and actual years.

$$
F_{m}=\frac{\sum_{i=1}^{n} \sum_{j=1}^{4} \bar{P}_{i}^{j, v-1} q_{i}^{j, v-1}}{\sum_{i=1}^{n} \sum_{j=1}^{4} \bar{P}_{i}^{v-2} q_{i}^{j, v-1}}
$$

This method doesn't change the growth when comparing quarter I, with the same quarter of previous year because the link is referred to the same quarter to the previous year expressed with the prices of the same year.

In general is not a best method. The method used depends by the statistical data disposable and quality. Anyway most of the countries referred to the first one because of the advantages that it has compared with the other one. In this paper it is used the first method as the one used by most of the countries.

\section{Quarter to quarter growth rate in Kosovo}

Quarterly GDP in Kosovo is estimated by production and expenditure approach in current prices and in the average prices of the previous year. Until know quarterly GDP are not published seasonally adjusted even not chain linked. In those circumstances it is impossible to compare quarter to quarter growth rate in Albania but even quarter to the same quarter of previous year for Kosovo. In the case of Kosovo in order to adjust the main aggregates series, based on which the GDP is estimated through the production method, is used TRAMO-SEATS technique.

Because the time series are very short annual estimations are used to make a back cast of series for years 2008-2009. The back cast techniques are mostly regression methods (SARIMA models). The back cast data after that are benchmarked with annual data to be in consistence with them. The other problem that is present in Kosovo quarterly series is related with the fact that those are not chain linked. For this reason annual technique explained above is used for each of the quarterly time series. The last step of the work is related with seasonal adjustment. The reference period is from the first quarter 2008 until first quarter of year 2015.

Some of the quarterly series of economic sectors in Kosovo show a strong seasonality, like trade hotels and restaurants, while the effect of working days number and of the calendar is not significant. The seasonally adjusted series was obtained by removing this effect from the unadjusted series, by using additive or multiplicative regression model. The seasonally adjusted GDP is obtained through the indirect method, which eliminate the statistical discrepancy between the GDP and the sum of its components, which are independently seasonally adjusted. The GDP series with indirect approach is produced based on all economic sectors in each of the aggregated series is used direct method of seasonal adjusted.

Firstly is important to emphasize the characteristics of Kosovo. Many sectors of the economy such as the construction, trade, transport, etc., don't have certain rules on working days. Often in these sectors 
people work during all the week days and with no specified timetable. For this reason to these sectors is applied a calendar where are excluded the effects of working days. In other sectors like postcommunication or other services, which included public administration, financial activities, etc, is applied a calendar with working days as the holidays and weekend is applicable for this sectors.

In the Graph 1 are presented the series of GDP seasonal adjusted with indirect method and not seasonal adjusted series. From the graph can be seen that in the first quarter in original values the economy has low values compared with other quarters, something which has been eliminated in the adjusted series. It can be seen that the adjusted series doesn't follow the trend effect, but gives even the smoothly fluctuations which comes from the economic developments, the main objective of the seasonal adjusted series in the short-run.

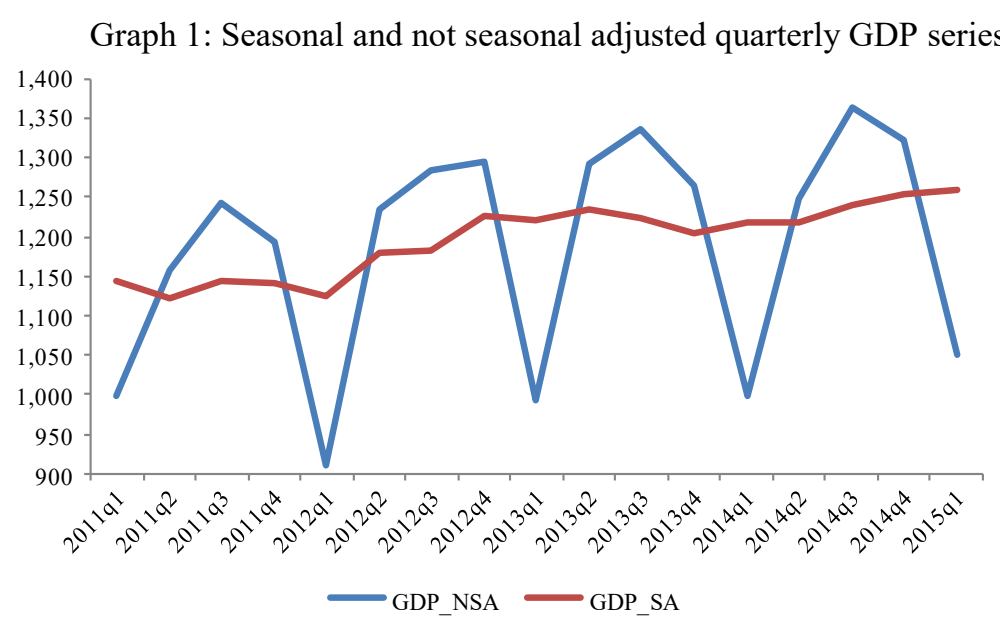

Source: Authors work

In graph 2 is shown quarter to quarter growth rate of GDP series estimated in both series; seasonal and not seasonal adjusted. In the not seasonal adjusted it is difficult to give opinion about the growth rate, as the seasonality is very significant. The same think can't be said for seasonal adjusted series.

\section{Graph 2: Seasonal and not seasonal adjusted quarter to quarter growth rate}

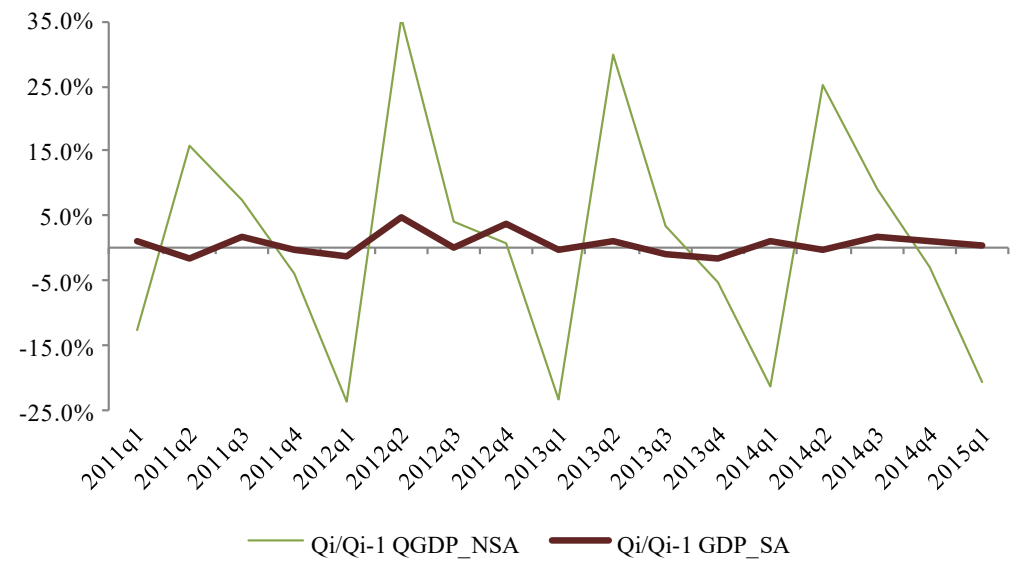

Source: Authors work

For a better understanding of growth rate in graph 3 is shown only the changes of seasonal adjusted series. Based on the results achieved can be said that Kosovo economy has had a positive growth with 
$0.4 \%$ compared with previous quarter. Interesting is the fact that even that the economy growth has been lower in 2014 the quarterly fluctuations have been much lower.

Graph 3: Quarter to quarter growth rate on seasonal adjusted quarterly GDP series

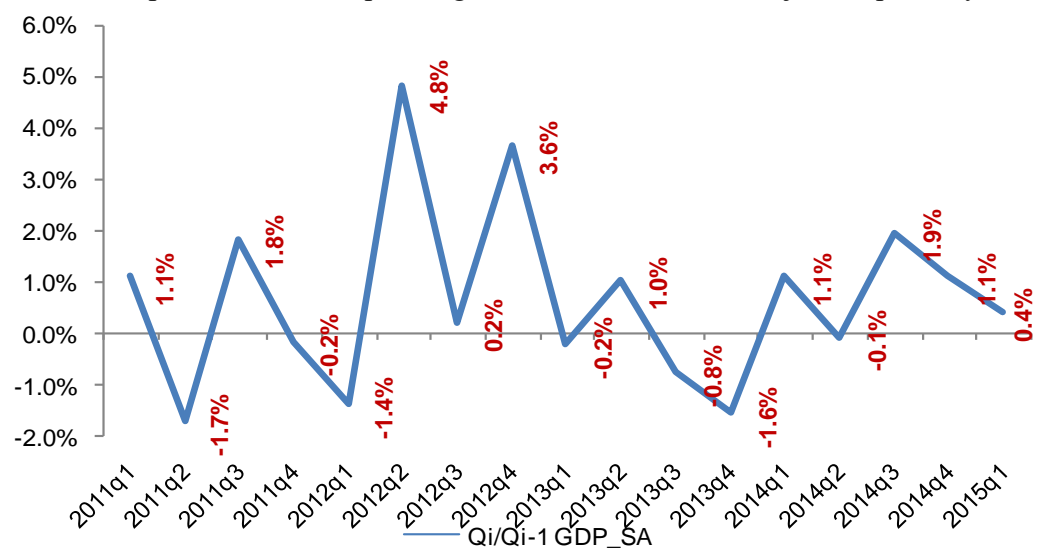

Source: Authors work

The lowest econimic growth for the estimated period has been in the second quarter of 2011 with $1.7 \%$ and the highst one has been in the second quarter of 2012 with $4.8 \%$.

As this study is base on the available published data it is posible to make other improvements based on more detailed information for quarterly time series of Kosovo by sector.

\section{Conclusions}

The purpose of this paper was to show the impact of seasonal adjustments in quarterly comparisons, more concretely quarterly economic growth rate.

Chain link is very important stage when working with quarterly series. It is a precondition for quarterly comparisons in constant prices.

Balancing quarterly series with annual one is very important to have coherence between two different frequencies series.

From the results achieved the lowest econimic growth for the estimated period has been in the second quarter of 2011 with $-1.7 \%$ and the highst one has been in the second quarter of 2012 with $4.8 \%$.

\section{References}

1. Agjencia e Statistikave të Kosovës, Seria 3. "Statistikat Ekonomike Bruto Produkti Vendor në baza tremujore (TM1-2010 - TM1-2014)”, Dhjetor 2014

2. Agjencia e Statistikave të Kosovës, Seria 3. "Statistikat Ekonomike Bruto Produkti Vendor në baza tremujore (2006 - 2012)", Dhjetor 2013

3. Agjencia e Statistikave të Kosovës, Seria 3. "Statistikat Ekonomike Bruto Produkti Vendor në baza tremujore (TM1-2015)"

4. Bloem. A, Dippelsman. R, and Mæhle. M, "Quarterly National Accounts Manual Concepts, Data Sources, and Compilation" International Monetary Fund, Washington DC, (2001), 125-145.

5. Burnett. M, "Seasonal adjustment of UK monetary aggregates: direct versus indirect approach", Monetary \& Financial Statistics: February 2006

6. Catherine C. Hood and David F. Findley, "Comparing Direct and Indirect Seasonal Adjustments of Aggregate Series", US Census Bureau, Washington, DC 202303.

7. European Communities, "Handbook on quarterly national accounts" 1999, 204-233. 
8. European Communities, "Seasonal Adjustment of European Aggregates: Direct versus Indirect Approach" (2001), 5-10.

9. Eurostat the Statistical Office of the European Commission "Seasonal Adjustment with Demetra Pedagogical Manual" May 2002.

10. Eurostat the Statistical Office of the European Commission, Task force on seasonal adjustment of quarterly National Accounts, Final Report, 10 January 2002.

11. Evans. Th, "Direct vs. Indirect Seasonal Adjustment for CPS National Labor Force Series", Bureau of Labor Statistics, Statistical Methods Staff, Washington, DC 20212, October 2009.

12. Guidelines on seasonal adjustment by Task force on Seasonal adjustment of QNA endorsed by the CMFB

13. Hindrayanto. I, "Seasonal adjustment: direct, indirect or multivariate method?" March (2004).

14. http://epp.eurostat.ec.europa.eu/portal/page/portal/national_accounts/methodology/quarterly_ac counts

15. Maravall. A, "An application of the Tramo-Seats automatic procedure; direct versus indirect adjustment”, August (2005). 